\title{
Water Resource Management Frameworks in Water-Related Adaptation to Climate Change
}

\author{
Godfrey Odongtoo, Denis Ssebuggwawo, and Peter Okidi Lating
}

\section{Contents}

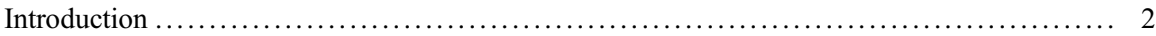

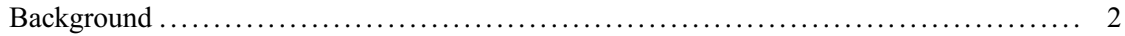

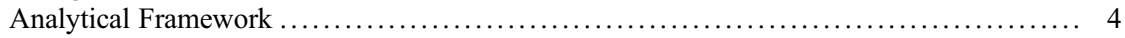

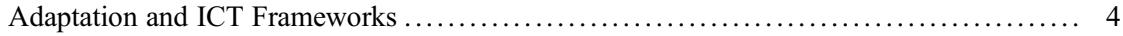

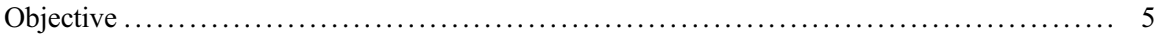

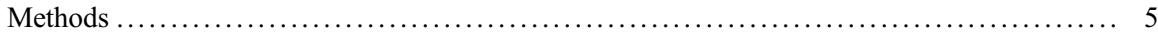

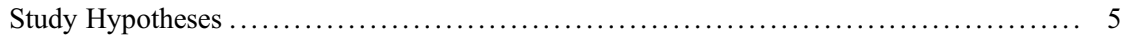

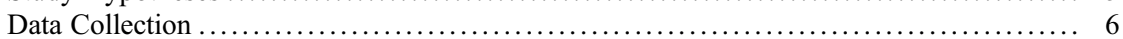

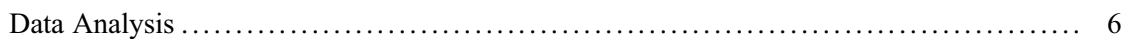

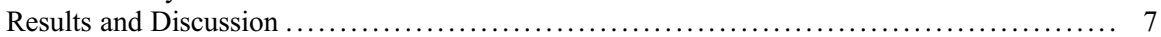

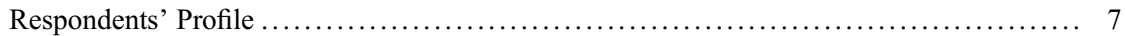

Demographic Information of the Respondents $\ldots \ldots \ldots \ldots \ldots \ldots \ldots \ldots \ldots \ldots \ldots \ldots \ldots \ldots$

Evaluation of Outer Measurement Model $\ldots \ldots \ldots \ldots \ldots \ldots \ldots \ldots \ldots \ldots \ldots \ldots \ldots \ldots \ldots \ldots .8$

This chapter was previously published non-open access with exclusive rights reserved by the Publisher. It has been changed retrospectively to open access under a CC BY 4.0 license and the copyright holder is "The Author(s)". For further details, please see the license information at the end of the chapter.

G. Odongtoo $(\bowtie)$

Department of Computer Engineering, Busitema University, Tororo, Uganda

Department of Information Technology, Makerere University, Kampala, Uganda

D. Ssebuggwawo

Department of Computer Science, Kyambogo University, Kampala, Uganda

e-mail: dssebuggwawo@kyu.ac.ug

P. O. Lating

Department of Electrical \& Computer Engineering, Makerere University, Kampala, Uganda e-mail: plating@cedat.mak.ac.ug 


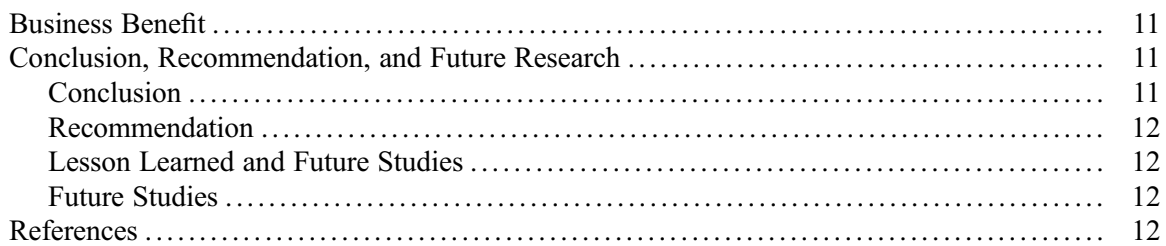

\section{Abstract}

This chapter addresses the use of partial least squares-structural equation modeling (PLS-SEM) to determine the requirements for an effective development of water resource management frameworks. The authors developed a quantitative approach using Smart-PLS version 3 to reveal the views of different experts based on their experiences in water-related adaptation to climate change in the Lake Victoria Basin (LVB) in Uganda. A sample size of 152 was computed from a population size of 245 across the districts of Buikwe, Jinja, Mukono, Kampala, and Wakiso. The chapter aimed to determine the relationship among the availability of legal, regulatory, and administrative frameworks, public water investment, price and demand management, information requirements, coordination structures, and analytical frameworks and how they influence the development of water resource management frameworks. The findings revealed that the availability of legal, regulatory, and administrative frameworks, public water investment, price and demand management, information requirements, and coordination structures had significant and positive effects on the development of water resource management frameworks. Public water investment had the highest path coefficient $(\beta=0.387$ and $p=0.000)$, thus indicating that it has the greatest influence on the development of water resource management frameworks. The $\mathrm{R}^{2}$ value of the model was 0.714 , which means that the five exogenous latent constructs collectively explained $71.4 \%$ of the variance in the development. The chapter suggests putting special emphasis on public water investment to achieve an effective development of water resource management frameworks. These findings can support the practitioners and decision makers engaged in water-related adaptation to climate change within the LVB and beyond.

\section{Keywords}

Climate change $\cdot$ Lake Victoria Basin $\cdot$ PLS-SEM $\cdot$ Water resource management frameworks

\section{Introduction}

\section{Background}

There is an increasing pressure on water resources in the Lake Victoria Basin (LVB) due to rapid population growth, increased urbanization and industrialization, uncontrolled environmental degradation, and pollution (Dauglas et al. 2014; 
Bakibinga-ibembe et al. 2011). These pressures still remain as a big challenge to the sustainable management of water resources (Mongi et al. 2015). Moreover, the LVB remains to be an important water resource for five countries, namely, Uganda, Kenya, Tanzania, Rwanda, and Burundi. The LVB is the largest freshwater lake in Africa with a surface area of $68,800 \mathrm{~km}^{2}$. It provides resources for fishing, agriculture, medicine, forestry, water transport, and other economic activities (Odongtoo et al. 2018). Its surrounding area is affected by increasing commercial activities and inadequate provision of sanitation services, among others (Okurut 2010; Wafula et al. 2014). These affect the landscape and water resources around the lake, making the water unsuitable for use.

According to Oyoo-Okoth et al. (2010), there is a combination of four analyzed heavy metals in the water samples of the LVB showing similar presence of heavy metal in the waters within the lake. This can be attributed to the fact that human activities, such as industrialization and agricultural practices, seriously contribute to the degradation and pollution of the environment, which adversely affect the water bodies, as noted by Devi et al. (2018). Increased human activities, such as poor land use, uncontrolled abstractions, and water pollution, greatly reduce the quantity and quality of the available water resources.

Globally, water resources are facing severe degradation due to pollution and inefficient water resource management strategies (Wang et al. 2015). It has been reported that water pollution causes approximately 14,000 deaths per day, mostly due to drinking water contamination caused by untreated sewage in developing countries (Devi et al. 2018). Rinawati et al. (2013) argued that these challenges create potential major threats to global biodiversity around water bodies, such as the LVB. The above authors further observed that this is true of the biodiversity around LVB as noted by Case (2006). The most recent statistics show that cities and small towns within the LVB are rapidly growing (Dauglas et al. 2014). The best examples of the growth pattern of towns and cities can be observed in Mwanza in Tanzania, Jinja and Port Bell in Uganda, and Kisumu in Kenya. Both population growth and urbanization have negative impacts on the quality and quantity of water resources. Some of these impacts include eutrophication and siltation, in addition to water pollution, as a result of increased runoff from bare lands as deforestation persists around the LVB (Ondieki 2015). Muhweezi (2014) also noted that biodiversity and ecosystem-specific goods and services around the LVB are likely to be adversely affected in the future by water pollution. It can be inferred that these challenges revolve around poor management of water resources. Failure to address such challenges will cause serious problem to the lives of many people who depend on the LVB.

Poor management of the scarce water resources can lead to climate change. The climate is continuously changing and is getting worse over time. Moreover, extreme weather conditions are occurring more frequently than before, thus negatively affecting the agricultural sector, consequently leading to food shortages. Farmers from different age groups acknowledge an increase in temperature, and they agree that the temperature is increasing with time (Mongi et al. 2015). 
According to Leal et al. (2015), water is one of the essential resources for human being, and its availability has great impacts on the environmental, political, and economic situations. This means that water resources have to be managed well. Water resource management is the activity of planning, developing, distributing, and managing the optimum use of water resources (Okurut 2010). Ssozi et al. (2015) defined water resource management as the development of political, social, economic, and administrative systems to develop and manage water resources. According to the technical committee of the Global Water Partnership, Integrated Water Resources Management (IWRM) is a process that promotes the coordinated development and management of water, soil, and other related resources to maximize the resultant economic and social welfare in an equitable manner without compromising the sustainability of vital ecosystem (ITU-T 2010).

\section{Analytical Framework}

Water resource management has been recently developed due to the improvement in water technology, natural events, economic developments, and changing social needs. The current trend in water management changed from technical to a combination of technical and sociopolitical perspectives (Demetropoulou et al. 2010). This led to an increase in stakeholders and public participation. It is therefore necessary to establish a framework to guide practitioners and managers in water resource management. For managers and decision makers to conduct good analysis, it is necessary to use analytical frameworks to promote logical thinking in a systematic manner.

\section{Adaptation and ICT Frameworks}

According to Akoh et al. (2011), the frameworks of Information and Communication Technology (ICTs) in mitigating climate change and adaptation are still relatively new. Frameworks on adaptation to climate change can be considered in three ways: first, to emphasize the potential of ICTs to reduce vulnerability to climate change by building resilience; second, to focus on delivering different types of information needed to achieve effective climate change adaptation; and third, to emphasize a disaster risk management framework focusing on the reduction of community vulnerabilities and management and recovery from emergencies as they arise.

According to the 1992 Dublin Conference on water and the Rio de Janeiro Summit on sustainable development (White 2013), the four key principles adopted were as follows: first, freshwater is a finite and vulnerable resource essential to life, development of irrigation, industrial and transport sector, and the environment; second, water development and management should be based on a participatory approach, involving users, planners, and policy makers at all levels; three, women play a central part in the provision, management, and safeguarding of water; and fourth, water has an economic value in all its competing uses and should be recognized as an economic good. 


\section{Objective}

The objective of this chapter was to apply a PLS-SEM to evaluate the requirements for the development of water resource management framework in water-related adaptation to climate change in Uganda's side of the LVB.

\section{Methods}

In evaluating the requirements for the development of water resource management framework in water-related adaptation to climate change, PLS-SEM was used. The proposed model was analyzed in two different stages: first, the model was composed of measurement models that define the relationship between latent indicators and their manifest variables, and second, a structural model showing the relationship between the manifest variables. A total of 24 factors which were obtained from the literature review were named as the observed variables and were divided into six groups: availability of legal, regulatory, and administrative frameworks, analytical framework, public water investment, information requirements, coordination structures, and pricing and demand management. These six groups were called exogenous latent constructs. Thus, an effective water resource management framework is influenced by the six major constructs.

\section{Study Hypotheses}

Based on the objectives of the research, the hypothesized model was developed. Quantitative data to test the hypothesis was collected from experts in water resource sectors and was subjected to Smart-PLS test. Some of the hypotheses passed the test and were therefore accepted, whereas the others that failed the test were rejected. Hypothesis 1 (H1): Availability of legal, regulatory, and administrative frameworks has a significant and positive effect on the development of water resource management frameworks. Hypothesis 2 (H2): Analytical framework has a significant and positive effect on the development of water resource management frameworks. Hypothesis 3 (H3): Public water investment has a significant and positive effect on the development of water resource management frameworks. Hypothesis $4(\mathrm{H} 4)$ : Information requirements has a significant and positive effect on the development of water resource management frameworks. Hypothesis 5 (H5): Coordination structures has a significant and positive effect on the development of water resource management frameworks. Hypothesis 6 (H6): Pricing and demand management has a significant and positive effect on the development of water resource management frameworks. This hypothesis design was adapted from Shahid et al. (2018). 


\section{Data Collection}

The data collection procedures involved three important phases. In the first phase, preliminary variables were obtained to formulate hypotheses using the materials in the review of literature, such as books, journals, and conference materials. In phase two, a pilot study was conducted to ensure consistency and completeness to help modify the questionnaire. Lastly, the questionnaire survey was conducted to obtain the opinion of the respondents. This study procedure was adapted from Shahid et al. (2018). Data collection was performed in the Buikwe, Jinja, Mukono, Kampala, and Wakiso districts in Uganda. The above districts were chosen based on the fact that those areas heavily depend on the LVB and at the same time were immensely affected by the decline in water resources. The key stakeholders that were engaged in this chapter included employees from the LVB Commission, the LV Fishery Organization, District Environmental Officers, District Forestry Officers, NEMA, Ministry of Water and Environment, National and Regional Policymaking and Communication Organs, and key community leaders. To calculate the sample size, Slovin's formula was used, $\mathrm{n}=\frac{N}{1+N e^{2}}$, where $n$ denotes the sample size, $N$ denotes the population size, and $e$ denotes the error margin. The population size of 245 was used with a confidence interval of $95 \%$ and error margin of $5 \%$, generating a sample size of 152 .

The questionnaire was composed of two sections. Section one consisted of the respondents' personal information. Section two consisted of variables appropriately grouped into six categories based on the nature of the measurements/constructs: availability of legal, regulatory, and administrative frameworks (LRA), analytical frameworks (AF), public water investment (PW), information requirements (IR), coordination structures (CS), and pricing and demand management. The questionnaires were administered to different stakeholders with an experience of more than 5 years in the water resource sector, such as executives, managers, water engineers, and IT officers. During the 4 months of study, valuable opinions from experts were obtained and incorporated in the model.

\section{Data Analysis}

The hypothesized structural model was analyzed using Smart-PLS version 3. SmartPLS has advantages over other regression-based methods: First, it is capable of evaluating several latent constructs with various manifest variables and is considered as the best technique for multivariate analysis (Shahid et al. 2018). Second, it is suitable for evaluating the constructs when the sample size is less than 200 in comparison with other SEM software, such as AMOS, which require a sample size of more than 200. In this specific chapter, the sample size was 152 and therefore justifies the use of Smart-PLS. Smart-PLS involves a two-step procedure, namely, evaluation of the outer measurement model and evaluation of the inner structural model (Henseler et al. 2009). 


\section{Results and Discussion}

\section{Respondents' Profile}

Table 1 shows the demographic information of the respondents. The respondents were selected from a wide range of professionals engaged in the water resource sector. About $61.8 \%$ of the interviewed experts were male. Majority of the interviewed individuals were in the middle age group (30-39 years) $(34.9 \%)$, followed by the young age group (20-29 years) $(31.6 \%),(40-49)$ years were $23.7 \%$. Those aged 50 years and above only accounted for $9.9 \%$ of the total population. This research is part of a bigger study conducted to develop a water resource management ICT model in the LVB.

\section{Demographic Information of the Respondents}

In Table 1, the highest percentage (44.7\%) of the respondents have acquired master's degree, followed by bachelor's degree (44.1\%), diploma (8.6\%), and $\mathrm{PhD}(2.6 \%)$. The highest category of workers $(65.8 \%)$ was staff/employee, followed by

Table 1 Demographic information

\begin{tabular}{l|l|r}
\hline Response item & Count & Percent \\
\hline Gender Distribution & & \\
\hline Female & 58 & 38.2 \\
\hline Male & 94 & 61.8 \\
\hline Total & 152 & 100.0 \\
\hline Age Group & & \\
\hline $20-29$ years & 48 & 31.6 \\
\hline $30-39$ years & 53 & 34.9 \\
\hline $40-49$ years & 36 & 23.7 \\
\hline $50-59$ years & 14 & 9.2 \\
\hline Above 59 years & 1 & 0.7 \\
\hline Total & 152 & 100.0 \\
\hline Qualification & & \\
\hline PhD & 4 & 2.6 \\
\hline Masters & 68 & 44.7 \\
\hline Bachelors & 67 & 44.1 \\
\hline Diploma & 13 & 8.6 \\
\hline Total & 152 & 100.0 \\
\hline Designation & & \\
\hline Manager/Administrator & 33 & 21.7 \\
\hline Staff/Employee & 100 & 65.8 \\
\hline Systems Administrator & 8 & 5.3 \\
\hline Client/Customer & 1 & 0.7 \\
\hline Total & 152 & 100.0 \\
\hline & &
\end{tabular}


managers/administrators $(21.7 \%)$, system administrators $(5.3 \%)$, and ICT technicians $(6.6 \%)$.

The level of education, the designation, the age, and the sex have significant effects on the perception of a person with regard to information. Older people tend to have more experiences, whereas highly educated ones display more in-depth knowledge on the subject matter of research. A low level of education has an impact on the use and adoption of technologies. The designation status is related more to the skills in the management of water resources. This promoted trust on the outcome of this study.

\section{Evaluation of Outer Measurement Model}

\section{Outer Loading}

In order to determine whether what was hypothesized was in line with the collected data, PLS-SEM was employed. PLS-SEM is very suitable for theory building and for examining the complex relationship of the models. The outer measurement model was used to calculate the reliability, internal consistency, and validity of the observed variables together with the unobserved variables (Gabriel et al. 2016). Consistency evaluations were based on a single observed and construct reliability tests, whereas convergent validity and discriminant validity were used for validity assessment. The observed variables with an outer loading of at least 0.7 are acceptable and should therefore be retained, whereas those with values less than 0.7 should be dropped (Shahid et al. 2018; Smith et al. 2014). From Table 2, the outer loadings of the retained variables ranged between 0.819 and 0.917 which are more than 0.7 and therefore valid. The variables, namely, collection and allocation, reuse of waste water, and water resource management, were dropped since their outer loading were below 0.7. Composite reliability (CR) was used for internal consistency evaluation in the construct reliability.

Table 2 Construct reliability and validity

\begin{tabular}{|c|c|c|c|c|c|}
\hline Main constructs & Item & $\begin{array}{l}\text { Outer } \\
\text { loading }\end{array}$ & $\begin{array}{l}\text { T- } \\
\text { statistics }\end{array}$ & $\mathrm{CR}$ & AVE \\
\hline \multirow{2}{*}{$\begin{array}{l}\text { Availability of legal, regulatory, and } \\
\text { administrative Frameworks }\end{array}$} & LRA2 & 0.799 & 12.766 & \multirow[t]{2}{*}{0.812} & \multirow[t]{2}{*}{0.683} \\
\hline & LR3 & 0.853 & 16.156 & & \\
\hline \multirow[t]{2}{*}{ Coordination structures } & $\mathrm{CS} 2$ & 0.773 & 10.034 & \multirow[t]{2}{*}{0.839} & \multirow[t]{2}{*}{0.724} \\
\hline & CS4 & 0.922 & 40.008 & & \\
\hline \multirow[t]{2}{*}{ Information requirements } & IR1 & 0.890 & 34.942 & \multirow[t]{2}{*}{0.886} & \multirow[t]{2}{*}{0.796} \\
\hline & IR2 & 43.681 & 43.681 & & \\
\hline \multirow[t]{2}{*}{ Public water investments } & PWI1 & 13.500 & 13.5 & \multirow[t]{2}{*}{0.742} & \multirow[t]{2}{*}{0.591} \\
\hline & PWI3 & 9.463 & 9.463 & & \\
\hline \multirow[t]{2}{*}{ Price and demand managements } & PDM2 & 14.359 & 14.359 & \multirow[t]{2}{*}{0.810} & \multirow[t]{2}{*}{0.681} \\
\hline & PDM3 & 19.859 & 19.859 & & \\
\hline
\end{tabular}




\section{Average Variance (AVE)}

To establish convergent validity on the construct, average variance extracted (AVE) is normally used. It is the grand mean value of the squared loadings of the indicators associated with the construct and is the sum of the squared loadings divided by the number of indicators. An AVE value of at least 0.50 shows that the construct explains more than half of the variance of its indicators (Hair et al. 2011). As shown in Table 2, the AVE values are greater than 0.5; therefore, both their convergent validity and internal validity are acceptable for this measurement model. In Table 3, the cross-loading of all observed variables are greater than the inter-correlations of other constructs in the model. The Fornell-Larcker criterion is a very good approach for assessing discriminant validity. It compares the square root of the AVE values with the latent variable correlations. The square root of each construct's AVE should be greater than its highest correlation with any other construct (Shahid et al. 2018). Therefore, these findings confirmed the cross-loading assessment standards which provided acceptable validation for the discriminant validity of the measurement model.

Using the t-test approach, some of the items that measure each construct were either retained or dropped, depending on whether the t-values are more or less than 2.76. The t-values must be greater than 2.76 for it to be retained as a measure for the variable (Hair et al. 2013; Shadfar and Malekmohammadi 2013). In Table 2, all the tvalues of the retained items in measuring each construct are greater than 2.76.

\section{Estimation of Path Coefficients (b) and P-values}

The significance of the hypotheses was tested by calculating the beta $(\beta)$ values. The $\beta$ values indicate the measure of the effect the variable has on the model. The higher the values, the stronger the effect, and it is always $<1$. As shown in Table 4 , both the $\beta$ and $p$ values of every path in the hypothesized model were calculated.

Table 3 Discriminant validity for water resource management frameworks

\begin{tabular}{l|l|l|l|l|l}
\hline & $L R A$ & $C S$ & $I R$ & PDM & PDM \\
\hline $\begin{array}{l}\text { Availability of legal, regulatory, and administrative } \\
\text { frameworks (LRA) }\end{array}$ & 0.827 & & & & \\
\hline Coordination structures (CS) & 0.615 & 0.851 & & & \\
\hline Information requirements(IR) & 0.092 & 0.135 & 0.892 & & \\
\hline Price and demand management (PDM) & 0.532 & 0.575 & 0.072 & 0.825 & \\
\hline Public water investment (PWI) & 0.029 & 0.067 & 0.308 & 0.054 & 0.769 \\
\hline
\end{tabular}

Table 4 Path coefficient

\begin{tabular}{l|l|l}
\hline Hypothesized path & Standardized $\beta$ & P-values \\
\hline Availability of legal, regulatory, and administrative frameworks & 0.244 & 0.000 \\
\hline Coordination structures (CS) & 0.206 & 0.001 \\
\hline Information requirements(IR) & 0.335 & 0.000 \\
\hline Price and demand management (PDM) & 0.211 & 0.000 \\
\hline Public water investment (PWI) & 0.387 & 0.000 \\
\hline
\end{tabular}


Fig. 1 The graphical representation of all path coefficients of the water resource management frameworks

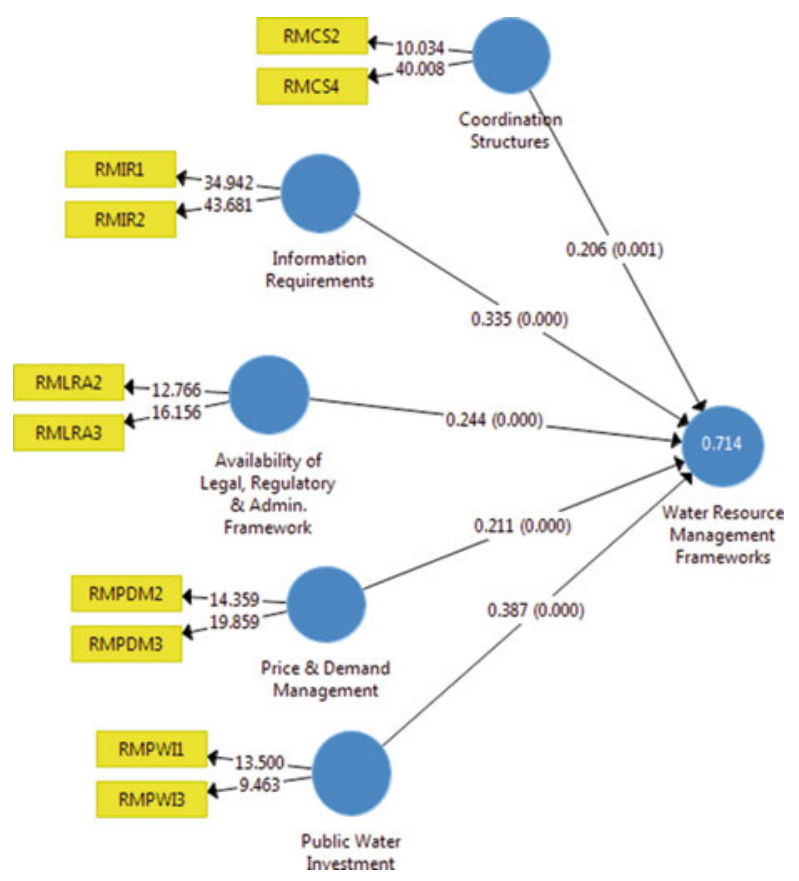

In (H1), researchers hypothesized that availability of legal, regulatory, and administrative frameworks would significantly and positively influence the development of water resource management frameworks. The findings in Table 4 and Fig. 1 confirm that Availability of Legal, Regulatory, and Administrative Frameworks of water-related factor significantly influenced the development of water resource management frameworks $(\beta=0.244, p<0.000)$. Hence, H1 was excellently confirmed. Furthermore, the findings from Table 4 and Fig. 1 hypothesized that the $(\mathrm{H} 3)$ public water investment-related factor positively influenced the development of water resource management frameworks $(\beta=0.387, p<0.000)$, showing that (H3) was effectively approved. Information requirements (IR) significantly and positively influenced the development of water resource management frameworks $(\beta=0.335, p<0.000)$. Coordination structure (CS)-related factor was positive and significant $(\beta=0.206, p<0.001)$, thus greatly supporting. The effect of price and demand management-related factor $(\beta=0.211 p<0.000)$ was also confirmed, thereby supporting (H6). The greater the $\beta$ coefficient, the stronger the effect of an exogenous latent construct on the endogenous latent construct. Analytical frameworks were dropped from the list because they failed both the t-test and the outer loading test.

The $\mathrm{R}^{2}$ value of the model was 0.714 , which means that the five exogenous latent constructs collectively explained $71.4 \%$ of the variance in the development of water resource management frameworks. The study suggests putting special emphasis on 
the public water investment factor to achieve an effective development of water resource management frameworks. These findings can support the practitioners and decision makers engaged in water-related adaptation to climate change within the LVB and beyond.

\section{Limitation of the Study}

The limitation and constraint of the chapter came from the fact that it was not possible to visit all the countries of the East African Community due to logistical constraints. This will be part of the future works when the current logistical constraints are solved.

\section{Business Benefit}

In accordance with the complete analysis of the measurement models and structural model, some of the hypotheses were statistically significant and hence were accepted, whereas the others failed the analysis. The results of this chapter support a richer and accurate picture of the factors influencing the development of effective water resource management frameworks. It is therefore important to consider the availability of legal, regulatory, and administrative frameworks, coordination structures, information requirements, price and demand management, and public water investment factors in the development of effective water resource management frameworks. The information obtained from this chapter will also enrich the body of knowledge that will benefit other researchers in the field of water resource management.

\section{Conclusion, Recommendation, and Future Research}

\section{Conclusion}

The key contribution of this chapter was the empirical identification of the constructs that can influence the development of effective water resource management frameworks and also the investigation of the fundamental issues affecting the constructs observed by water experts in the LVB. The results of the chapter revealed that availability of legal, regulatory, and administrative frameworks, coordination structures, information requirements, price and demand management, and public water investment had significant positive effects on the development of water resource management frameworks. This therefore suggests that emphasis should be put on the above variables. The final results of the partial least squares-structural equation modeling revealed that public water investment had the highest path coefficient $(\beta=0.387)$, thus indicating a major influence on the water resource management frameworks. Therefore, water resource managers should pay more attention to public water investment factors during the development of water resource management frameworks. 


\section{Recommendation}

This chapter recommends that for a successful development of water resource management frameworks, emphasis should be put on availability of legal, regulatory, and administrative frameworks, coordination structures, information requirements, price and demand management, and public water investment. Since public water investment had the highest path coefficient $(\beta=0.387)$ with a major overall influence on the development of water resource management frameworks, more emphasis should be put on it.

\section{Lesson Learned and Future Studies}

This chapter revealed that majority of the people engaged in different activities around the LVB are unaware of the dangers posed by their economic activities. Moreover, the local leaders lack effective and efficient means of disseminating and sharing information on the LVB and the impact of human activities on ecosystems, biodiversity, and water resources.

\section{Future Studies}

The areas for further research may focus on the study of how effective water resource management frameworks influence the design of an effective water resource management ICT model for an integrated water resource management of the LVB .

\section{References}

Akoh B, Livia B, Perry J-E, Creech H, Karami J, Echeverria D, ... Gass P (2011) Africa transformation-ready: the strategic application of information and communication technologies to climate change adaptation in Africa. Prepared for the African Development Bank, the World Bank and the African Union, Bristol

Bakibinga-ibembe DJ, Said AV, Mungai WN (2011) Environmental laws and policies related to periodic flooding and sedimentation in the Lake Victoria Basin of East Africa. Afr J Environ Sci Technol 5(5):367-380

Case (2006) Climate change impacts on East Africa. A review of the scientific literature. WWFWorld Wide Fund for Nature (formerly World Wildlife Fund), Gland

Dauglas WJ, Hongtao W, Fengting L (2014) Impacts of population growth and economic development on water quality of a lake: case study of Lake Victoria Kenya water. Environ Sci Pollut Res 21:5737-5746. https://doi.org/10.1007/s11356-014-2524-5

Demetropoulou L, Nikolaos N, Papadoulakis V, Tsakiris K, Koussouris T, Kalogerakis N, Koukaras $\mathrm{K}$ (2010) Water framework directive implementation in Greece: introducing participation in water governance - the case of the Evrotas River Basin Management Plan. Environ Policy Gov 20:336-349

Devi SP, Jothi S, Devi A (2018) Data mining case study for water quality prediction using R tool. Int J Sci Res Comput Sci Eng Inform Technol 3(1):262-269 
Gabriel C, Christian MR, Jörg H, José L (2016) Prediction-oriented modeling in business research by means of PLS path-modeling. J Bus Res 69(10):4545-4551

Hair JF, Ringle C, Sarstedt M (2011) PLS-SEM: indeed a silver bullet. Market Theory Pract 19:139-151

Hair FJ, Ringle MC, Sarstedt M (2013) Partial least square structural equation modelling: rigorous application, better results and higher acceptance. Long Range Plan 46:1-12

Henseler J, Ringle C, Sinkovics R (2009) The use of partial least squares path modeling in international marketing. Adv Int Market 20:277-319

Leal FW, Trincheria DJ, Vogt J (2015) Towards sustainable water use: experiences from the projects AFRHINET and Baltic flows. In: Leal Filho W, Sümer V (eds) Sustainable water use and management, green energy and technology. Springer, Cham

Mauree V (2010) ICT as an enabler for smart water management. ITU-T Technology Watch Report, ITU Telecommunication Standardization Bereau, p 23

Mongi HJ, Mvuma AN, Kucel S, Tenge AJ, Gabriel M (2015) Accessibility and utilization of mobile phones for governance of water resources in the Lake Victoria Basin: constraints and opportunities in Tanzania. Afr J Environ Sci Technol 9(5):438-450

Muhweezi AB (2014) An overview of climate change and biodiversity in Uganda. African and Latin American Resilience to Climate Change Project. https://doi.org/AID-OAA-TO-11-00064

Odongtoo G, Ssebugwawo D, Okidi LP (2018) Factors affecting communication and information sharing for water resource management in Lake Victoria. In: Handbook of climate change and biodiversity. Springer, Cham, pp 211-222

Okurut T (2010) Integrated environmental protection approaches: strengthening the role of water supply operators in resource conservation. In: 15th international African water congress and exhibition commonwealth resort, Munyonyo, Kampala, Uganda

Ondieki MC (2015) Aspects of water quality and water pollution control in vulnerable environments. J Geogr Earth Sci 3(2):83-93

Oyoo-Okoth E, Wim A, Osano O, Kraak MHS, Ngure V, Makwali J, Orina PS (2010) Use of the fish endoparasite ligula intestinalis (L., 1758) in an intermediate cyprinid host (Rastreneobola argentea) for biomonitoring heavy metal contamination in Lake Victoria, Kenya. Lakes Reserv Res Manag 15:63-73

Rinawati F, Stein K, Lindner A (2013) Climate change impacts on biodiversity - the setting of a lingering global crisis. Biodiversity 5:114-112

Shadfar S, Malekmohammadi I (2013) Application of structural equation modeling (SEM) in restructuring state intervention strategies toward paddy production development. Int J Acad Res Bus Soc Sci 3(12):576

Shahid H, Fangwei Z, Ahmed FS, Ali Z, Muhammad SS (2018) Structural equation model for evaluating factors affecting quality of social infrastructure projects. Open Access J Sustain 10:1415

Smith RG, Davis AS, Jordan NR, Atwood LW, Daly AB, Grandy AS, ... Yannarell AC (2014) Structural equation modeling facilitates transdisciplinary research on agriculture and climate change. Crop Sci 54:475-483

Ssozi F, Blake E, Rivett U (2015) Designing for sustainability: involving communities in developing ICT interventions to support water resource management. https://doi.org/978-1-905824-51-9

Wafula JD, Wang H, Li F (2014) Impacts of population growth and economic development on water quality of a lake: case study of Lake Victoria Kenya water (Garrigues P, ed). Springer, Berlin/ Heidelberg

Wang Z, Song H, Watkins DW, Ong KG, Xue P, Yang Q, Shi X (2015) Cyber-physical systems for water sustainability: challenges and opportunities. IEEE Commun Mag 53(5):216-222

White C (2013) Integrated water resources management: what is it and why is it used? Retrieved from https://globalwaterforum.org/2013/06/10/integrated-water-resources-management-whatis-it-and-why-is-it 
Open Access This chapter is licensed under the terms of the Creative Commons Attribution 4.0 International License (http://creativecommons.org/licenses/by/4.0/), which permits use, sharing, adaptation, distribution and reproduction in any medium or format, as long as you give appropriate credit to the original author(s) and the source, provide a link to the Creative Commons license and indicate if changes were made.

The images or other third party material in this chapter are included in the chapter's Creative Commons license, unless indicated otherwise in a credit line to the material. If material is not included in the chapter's Creative Commons license and your intended use is not permitted by statutory regulation or exceeds the permitted use, you will need to obtain permission directly from the copyright holder.

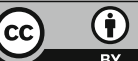

